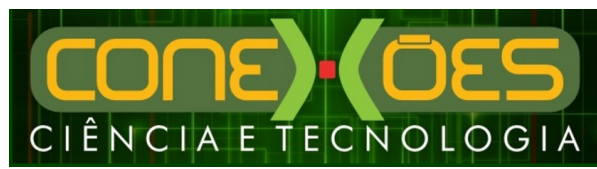

\title{
CRENÇAS DOS PROFISSIONAIS DE TURISMO SOBRE A RELEVÂNCIA DO ENSINO DE ESPANHOL COMO LÍNGUA ESTRANGEIRA - ELE
}

\author{
DeOClides Barros CASTElo Branco ${ }^{1}$, \\ Glauber Lima Moreira ${ }^{1}$, Adriana da Rocha CARVAlho ${ }^{2}$ \\ ${ }^{1}$ Universidade Federal do Piauí - UFPI \\ ${ }^{2}$ Instituto Federal de Educação Ciência e Tecnologia do Ceará - IFCE \\ Campus de Aracati \\ <deoclidesbranco@ outlook.com>, <glauberlimamoreira@ hotmail.com>. \\ $<$ adriana.carvalho@ifce.edu.br>
}

DOI: 10.21439/conexoes.v11i3.905

\begin{abstract}
Resumo. O presente estudo foi realizado para detectar as crenças acerca da relevância do aprendizado da língua espanhola para os profissionais do turismo em três hotéis e duas agências de viagem da cidade de Parnaíba (PI) e, também, para saber da sua importância para o turismo local. Acredita-se que as línguas estrangeiras (LEs) podem ser um diferencial competitivo profissional, pois o seu conhecimento e a aprendizagem do espanhol como língua estrangeira (ELE), no turismo, são de grande relevância. Para alcançar os objetivos deste trabalho, foi aplicado questionário com os sujeitos. A pesquisa realizada foi de caráter exploratório, descritiva e de campo, com abordagem qualitativa. Após a análise dos resultados, detectou-se que, para os profissionais de turismo, o ensino e a aprendizagem de uma LE, mais especificamente, o ensino de ELE é importante para todos que atuam nessa área. Contudo, entre as crenças verificadas, percebe-se que, para eles, a língua inglesa tem supremacia sobre as demais LEs no cenário mundial. Os informantes afirmam, ainda, que o espanhol não é critério de decisão de vaga em empresa turística na cidade; no entanto, é notória a necessidade da aprendizagem da referida língua para os sujeitos deste trabalho, sobretudo para o turismólogo.
\end{abstract}

Palavras-chaves: Aprendizagem de Espanhol. Crenças. Turismo.

\begin{abstract}
The present study was carried out to keep track of the beliefs concerning the relevance of Spanish Language Learning to the tourism professionals in three hotels and two travel agencies in the town of Parnaíba (PI); also, this study will be helpful to understand the importance of learning Spanish to the local tourism. It is common sense that the foreign languages (FLs) play an important role concerning professional competitiveness, so learning Spanish as a Foreign Language (SFL) might be a paramount. In order to achieve the goals set in this paper, a questionnaire was applied to the participants. This study was an exploratory, descriptive and field research with qualitative approach. After analyzing the data, it was highlighted the importance of learning a Foreign Language (FL), more specifically, it was identified that learning Spanish can be important for those who work with tourism. However, among the beliefs that emerged, it was perceived that English language still plays a leading role in the world. The respondents also state that the Spanish language does not interfere positively when a professional is to be hired in the city, however for the respondents of this study there is a necessity to learn this language, especially for the tourismologist.
\end{abstract}

Keywords: Spanish Learning. Beliefs. Tourism. 


\section{INTRODUÇÃO}

O mercado turístico está em constante processo de desenvolvimento, gerando, com isso, emprego e renda para o profissional da área. O turismo propicia o crescimento econômico da região onde é implementado, ampliando o campo de atuação do turismólogo e exigindo desse profissional dinamismo e conhecimentos linguísticos, especialmente em línguas estrangeiras, para que sua carreira seja eficaz.

Nesse contexto, a cidade de Parnaíba, que é rica em belezas naturais e em patrimônio histórico, vem se destacando como uma das mais importantes do Piauí no cenário turístico. Por isso, o profissional dessa área ganha espaço com a implementação dos serviços turísticos na comunidade, já que se têm observado novos visitantes/turistas brasileiros e estrangeiros hispanofalantes (hispanohablantes), proporcionando, dessa maneira, o desenvolvimento e crescimento local.

A expansão do turismo no Nordeste e, especificamente, na região do Piauí é vista como uma alternativa sustentável e viável, pois a região apresenta sol o ano inteiro, o que atrai turistas de regiões mais frias da Europa, América do Norte e até mesmo do Sul e Sudeste do Brasil. Tem-se percebido o aumento dos visitantes estrangeiros, sobretudo hispanohablantes, o que demanda o conhecimento da língua espanhola por parte do profissional que pretende receber bem esses visitantes. Acredita-se ser de grande relevância que esse profissional do turismo tenha conhecimento da língua dos visitantes (e outras) para que ele possa se comunicar sem maiores dificuldades.

Diante das especificidades e da complexidade dessa investigação, e, ainda, considerando a necessidade de delimitar um problema central de pesquisa, o presente estudo buscou averiguar a visão do profissional da área de turismo em relação ao ensino e ao conhecimento da língua espanhola para o desenvolvimento do turismo local, ou seja, detectar e analisar a relevância de se aprender a língua espanhola no tocante ao trabalho do turismo, e ainda, saber a importância da língua espanhola para o turismólogo da Parnaíba/PI.

Neste artigo, apresentamos sete seções: na primeira, expomos um breve panorama em relação ao ensino de língua estrangeira (doravante LE) no campo profissional; na segunda seção, discutimos a relevância da aprendizagem da LE no campo do turismo; e, no terceiro tópico, falamos sobre o ensino de Espanhol como Língua Estrangeira (doravante ELE) no turismo. $\mathrm{Na}$ quarta seção, apresentamos questões referentes às crenças dos profissionais de turismo sobre o ensino de ELE; e, em seguida, na quinta, temos a metodologia adotada neste trabalho; na sexta apresentamos a análise dos da- dos, e, finalmente, na sétima, as considerações desta investigação.

\section{FUNDAMENTAÇÃO}

\subsection{Domínio de língua estrangeira como diferen- cial competitivo profissional}

O conhecimento de uma LE é considerado pelos linguistas como uma ferramenta facilitadora que estreita as ligações comerciais e culturais, por conseguinte, gerando alterações na forma de interação entre os sujeitos envolvidos (TONDELLI, 2005, p.22). Dessa forma, acredita-se que o profissional de turismo precisa se comunicar muitas vezes em outro idioma; para tanto, fazse necessário o conhecimento satisfatório de uma LE para a realização de tarefas no seu ambiente de trabalho.

O senso comum de que o conhecimento de uma LE é importante nessa área motiva os estudantes que estão se preparando para ingressar na vida profissional a se capacitarem linguisticamente para serem mais competitivos. Hoje em dia, a concorrência é acirrada em todas as áreas, não se restringindo apenas a funcionários de empresas multinacionais que exercem cargos de direção e outros cargos importantes.

$\mathrm{Na}$ área de turismo, tem se intensificado cada vez mais a demanda por profissionais no mínimo bilíngues. De acordo com os estudos de Tondelli (2005) acerca da aprendizagem e conhecimento de outro idioma, hoje o mundo está em constante transformação, e, se não seguimos a evolução desse mundo contemporâneo, as chances de ascender profissionalmente serão minimizadas.

A autora acima afirma que a globalização ativou uma maior procura pelos estudos de uma língua estrangeira pelo motivo, principalmente, de desenvolvimento dos campos turísticos no Brasil. Desse modo, quem atua nessa área tem que se qualificar, no intuito de melhor receber tanto turistas domésticos quanto os visitantes estrangeiros. Falar a língua do turista significa mais confiança para esse, além de que o profissional poderá vender mais produtos e agregar valor ao serviço oferecido.

Essa preocupação sobre o domínio de LEs por profissionais de turismo já vem sendo problematizada em pesquisas há alguns anos no Nordeste do Brasil. Em 2003, Carvalho pesquisou a formação em inglês de profissionais de turismo na cidade de Fortaleza/CE. Nessa pesquisa foi constatada a insuficiência de profissionais que se comunicam em LEs (CARVALHO, 2003).

Na pesquisa de Carvalho (2003, p.40), foram analisadas as grades curriculares dos cursos técnicos e superiores na área de turismo, de modo a identificar a carga 
horária destinada ao ensino de LEs. Foi detectado que a carga horária de ensino de língua estrangeira (língua inglesa) não era suficiente para que o estudante alcançasse a proficiência que é exigida de um profissional da área de turismo.

Dessa forma, tendo ratificado que para o profissional da área de turismo é necessário o conhecimento de uma ou mais línguas estrangeiras e mesmo sabendo que nesse cenário o inglês é considerado como a língua dominante, devemos considerar também o conhecimento da língua espanhola, principalmente quando se constata a presença de hispanohablantes na cidade de Parnaíba onde foi conduzida esta pesquisa.

\subsection{A relevância de aprender uma LE para o mer- cado turístico}

São inegáveis as vantagens do domínio de uma língua estrangeira e o empoderamento que ele traz para os profissionais de uma maneira geral. No setor turístico, como já discutimos, essa competência é ainda mais vital, pois, com a globalização e a mobilidade que o transporte aéreo propicia, comunicar-se com pessoas de línguas diferentes é inevitável e essencial para a "sobrevivência" do mercado (trade) turístico.

A efetiva comunicação em língua estrangeira para esse fim requer a capacidade de se comunicar nas formas orais e escritas. Quando o profissional atinge essa meta, ele terá mais chances de êxito nas suas negociações corporativas. Acerca dessa temática, SancheS (1997, p.1) afirma que:

\footnotetext{
Ao destacar que o mercado de trabalho exige do profissional um conhecimento que vai além de simplesmente ler e escrever num outro idioma [...], o aperfeiçoamento em outro idioma como espanhol, italiano, francês, alemão, japonês ocorre pela facilidade que ele pode proporcionar ao profissional em um momento de negociação.
}

Como já foi mencionado anteriormente, é inegável o papel da língua inglesa no cenário do turismo; entretanto, a língua espanhola vem ganhando cada vez mais força, uma vez que é a segunda mais falada no mundo (SEDYCIAS, 2005). Considerando a geografia do Brasil, onde diversos países vizinhos têm o espanhol como língua oficial, falar essa língua pode significar alianças políticas e econômicas com eles.

A comunicação é um o processo linguístico complexo que leva em consideração os sujeitos envolvidos e a sua cultura. Ter uma aprendizagem eficaz em uma LE demanda conhecimento linguístico, mas também conhecimento acerca da cultura dos turistas de modo a desenvolver uma comunicação satisfatória entre o profissional da área de turismo e o visitante.

Por ser uma atividade econômica considerada primordial na sociedade moderna, os profissionais da área de turismo necessitam de atualização e preparo para manter uma adequada comunicação com os visitantes, pois esses precisam ser compreendidos em sua língua materna e, assim, suas expectativas serão atendidas eficazmente. Como bem afirma Tondelli (2005, p.22):

\begin{abstract}
Para o profissional da área industrial e/ou empresarial que se vê diante da necessidade de se comunicar adequadamente através de outro idioma, independentemente para os profissionais que já estão inseridos nas mais diversas áreas, quanto para aqueles que estão se preparando para ingressar no mercado de trabalho, que a cada dia se torna mais e mais competitivo, dominar um segundo idioma não se restringe mais a um universo exclusivo de pessoas, mas é sim uma necessidade básica na formação do indivíduo.
\end{abstract}

Parafraseando Corticeiro (2008), a autora afirma que o Turismo é, acima de tudo, visto como um produto de comodidade e de promover lazer e descanso aos consumidores que, para se sentirem bem em um país estrangeiro, têm que conseguir se comunicar, não estando forçados a usar a língua local.

Por isso, o aprendizado de uma LE proporciona uma abertura de muitas portas para o crescimento pessoal, profissional e cultural. O mercado de trabalho, atualmente, considera um requisito básico no momento da contratação que o candidato domine, pelo menos, uma LE. Kezen (2005, p.2) problematiza a questão de não se dominar uma língua estrangeira no Brasil:

\footnotetext{
O domínio de língua estrangeira auxilia o educando em seu processo de auto-afirmação, recuperação ou afirmação da auto-estima, à superação do sentimento de impotência que tão freqüentemente acomete os indivíduos das classes mais populares nos processos educativos na realidade brasileira.
}

Corroborando com o exposto, o domínio de um ou mais idiomas torna-se um diferencial competitivo na contratação de profissionais do setor de turismo e, também, em outras áreas, pois aqueles estão em contato direto com o turista, tendo em vista que essa interação entre as línguas é imprescindível para o turismólogo que almeja se destacar na sua carreira, ademais de apresentar um diferencial para obter sucesso nessa profissão que vem crescendo junto aos demais setores da economia. Tal conhecimento linguístico faz com que os dese- 
jos dos clientes ou uma simples informação possam ser repassados com clareza.

\subsection{O ensino/aprendizagem do espanhol como lín- gua estrangeira (ELE) no turismo}

A língua espanhola é atualmente uma das mais faladas no mundo referente ao turismo e às relações comerciais e culturais existentes entre os países participantes do Mercado Comum do Sul (MERCOSUL), perante o crescimento do turismo internacional e uma maior divulgação do Nordeste brasileiro. Segundo Sedycias (2005, p.38), o espanhol é uma das mais importantes línguas mundiais da atualidade. Para o pesquisador, a língua espanhola é:

A segunda língua autóctone mais falada no mundo [...]. Ela perde em número de falantes nativos apenas para o chinês mandarim. É língua oficial de vinte e um países sendo eles: Argentina, Bolívia, Colômbia, Costa Rica, Cuba, Chile, República Dominicana, Equador, El Salvador, Espanha, Guatemala, Guiné Equatorial, Honduras, México, Nicarágua, Panamá, Paraguai, Peru, Porto Rico, Uruguai, Venezuela.

Sendo assim, a aprendizagem do espanhol no Brasil e, mais especificamente, no Nordeste, promove uma maior facilidade do ingresso do futuro turismólogo no mercado de trabalho e, assim, faz com que os profissionais das principais atividades relacionadas ao turismo (e outras áreas) consigam se comunicar efetivamente, compreender uma pessoa estrangeira sem precisar estar fazendo gestos e, consequentemente, esse visitante poderá se comunicar e ser bem atendido na sua língua.

Desse modo, no âmbito acadêmico, diversas disciplinas proporcionam somente um conhecimento teórico (o que não é irrelevante); no entanto, a aprendizagem de uma LE, no caso, a espanhola, leva o aluno (futuro profissional em potencial) a uma prática diária, em sala e fora dela, a conhecer novas culturas por estar se relacionando com essas.

Diante de tantos benefícios que a competência em um idioma promove, a língua espanhola apresenta um leque de oportunidades de aprendizado e expectativas para a formação profissional aos que querem alavancar sua carreira. A língua castelhana é, portanto, uma das línguas que vem se desenvolvendo dentro do setor turístico e hoteleiro no âmbito brasileiro, por exemplo.

A comunicação é uma troca verbal entre falantes. É o processo que os atores utilizam para compreender o mundo do outro, e, nesta ocasião, a utilização de uma LE se torna essencial para o sucesso de transmissão de uma determinada mensagem. Castelli (2001) aborda que, por meio do ensino/aprendizagem de uma LE, pode-se acrescentar mais valor às pessoas, tornandoas mais capazes. Logo, a aprendizagem da língua espanhola oportuniza ao estudante da área de turismo e demais profissionais, ascensão profissional, ou seja, tal conhecimento favorece um leque de oportunidades no âmbito profissional, acadêmico e pessoal.

\subsection{As crenças acerca do ensino/aprendizagem de uma LE}

Um dos pontos que despertou interesse para o desenvolvimento deste estudo deveu-se ao tema ser de grande relevância para os profissionais do setor turístico, devido às necessidades desses em empregar a língua estrangeira como instrumento de trabalho. Para tanto, faz-se necessário conhecer as crenças que surgem no tocante à sua aprendizagem e importância de utilização no âmbito profissional dos agentes dessa área.

São vários os autores que estudam e conceituam crenças. De acordo com Barcelos (2001), Barcelos (2004), o conceito de crenças somente ganhou destaque nos anos 1990, com as pesquisas de Leffa (1991), Almeida Filho (1993). Como afirma Saboia (2012. p.275):

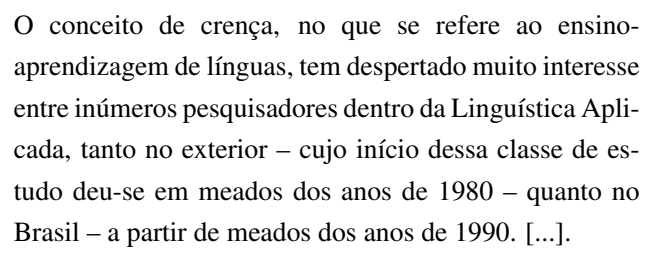

Para os teóricos Richards e Lockhart (1991), as crenças e valores dos discentes são pessoais, intuitivas e, muitas vezes, implícitas, formando a sua cultura de ensino. Certamente, essa é uma das mais importantes contribuições sobre o que vem a ser crença. Tal aporte teórico serviu de base para desenvolver a presente pesquisa acerca do estudo das crenças dos turismólogos que atuam na cidade de Parnaíba/PI.

Muitos profissionais de turismo ainda não valorizam suficientemente o ensino e a aprendizagem de uma língua estrangeira, acredita-se, aqui, que, talvez, eles acreditem que não irão precisar de tais conhecimentos para executar o seu trabalho.

Diante do exposto, faz-se necessário estabelecer uma relação entre as crenças dos profissionais que atuam no setor turístico e suas expectativas em relação ao mercado de trabalho. Busca-se, aqui, também, saber se essas crenças causam algum impacto (positivo ou negativo) no seu ambiente de trabalho. 
De acordo com as pesquisas (BARCELOS, 2004), observa-se que as crenças surgem, ainda, na universidade, durante o ensino da língua estrangeira, pois é durante o período acadêmico que surgem as maiores indagações sobre a importância do aprendizado do idioma e o seu valor para o profissional de turismo para que ele desenvolva suas atividades eficazmente.

Dessa forma, faz-se necessário conhecer efetivamente as crenças dos profissionais de turismo no tocante ao conhecimento do ensino de espanhol como língua estrangeira (doravante ELE). Diante do exposto, Barcelos e Abrahão (2006, p.18) declara que:

\footnotetext{
[Crenças são] uma forma de pensamento, construções da realidade, maneiras de ver e perceber o mundo e seus fenômenos, co-construídas em nossas experiências resultantes de um processo interativo de interpretação e (re)significação. Como tal, crenças são sociais (mas também individuais), dinâmicas, contextuais e paradoxais.
}

Alvarez e Silva (2007, p.200) versa sobre o conceito de crenças, buscando esclarecer o objetivo e interesse em desenvolver investigações na área da linguística Aplicada, referentes ao processo de ensino e aprendizagem de uma LE. Nesse ínterim, a autora apresenta a sua concepção de crenças como:

[...] a crença constitui uma firme convicção, opinião e/ou idéia que tem o indivíduo com relação a algo. Essa convicção está ligada a intuições que têm como base as experiências vivenciadas, o tipo de personalidade e a influência de terceiros, pois elas são construídas socialmente e repercutem nas suas intenções, ações, comportamento, atitude, motivações e expectativas para atingir determinado objetivo. Elas podem ser modificadas com o tempo, atendendo às necessidades do indivíduo e a redefinição de seus conceitos, se convencido de que tal modificação lhe trará benefícios.

Portanto, ao longo do presente artigo, vamos discorrer mais sobre as crenças desses profissionais quanto à importância do aprendizado de uma língua estrangeira, mais especificamente, do conhecimento da língua espanhola, e como elas podem ser trabalhadas para uma melhor qualificação realizada com profissionais turismólogos após eles usarem a língua estrangeira ao seu favor e, ainda, como ferramenta de comunicação no seu incremento individual.

\section{METODOLOGIA}

Esta pesquisa é de caráter exploratório qualitativa, com o objetivo de detectar as crenças dos profissionais de tu- rismo em Parnaíba (PI, Brasil). Tais sujeitos participantes são egressos do curso de Bacharelado em Turismo, na Universidade Federal do Piauí (UFPI), campus de Parnaíba (PI), em 2013.

Sobre o universo e os sujeitos da pesquisa, ela foi realizada em três hotéis e duas agências de viagens e turismo. Os informantes deste estudo foram dez profissionais de turismo, os quais estão denominados como INF.1, INF.2 até INF.10, correspondente a Informante 1 , Informante 2, continuamente até o Informante 10. Faz-se necessário mencionar que tais informantes atuam em três hotéis como recepcionistas, supervisores e responsáveis pelo setor de reservas, e os dois profissionais que atuam nas duas agências de viagens são consultores de vendas e agentes de viagens.

Compre ressaltar que para a efetivação do presente estudo, aplicou-se o questionário com dez perguntas abertas aos sujeitos que atuam no setor hoteleiro, o qual foi aplicado no dia treze de fevereiro de 2013. O questionário é uma série ordenada de perguntas a que os sujeitos responderam por escrito.

Após essa descrição da metodologia adotada para a presente investigação, a seguir, apresentam-se os resultados e a discussão dos dados coletados através do instrumento de pesquisa mencionado anteriormente.

\section{RESULTADO E DISCUSSÃO}

A primeira questão buscava analisar quais as maiores dificuldades que os turismólogos enfrentam e/ou encontram ao aprender uma língua estrangeira, especificamente o ensino da língua espanhola. Através do Gráfico 1 a seguir, podem observar os dados a respeito de tal assunto:

Gráfico 1: Dificuldades em aprender uma língua estrangeira

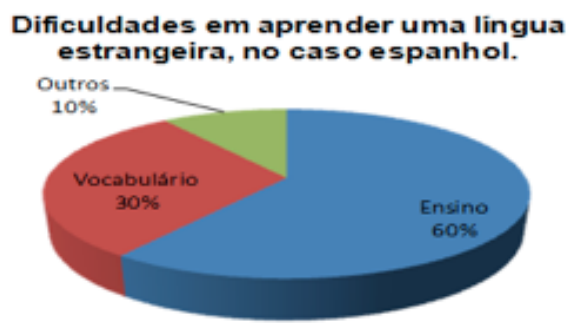

Fonte: Dados da pesquisa, 2013

Diante da análise da primeira questão do questionário aplicado com os dez turismólogos, pode-se afirmar que, dos dez turismólogos respondentes, seis afirmaram que a falta de Escolas de Idiomas é a maior dificuldade para se estudar e aprender uma língua estrangeira, no 
caso, o espanhol, pois os sujeitos afirmam que, na cidade de Parnaíba, eles não encontram muitas opções para estudar a língua espanhola, além de não existir, na cidade pesquisada, curso de idiomas ou curso de graduação em Letras-Espanhol, exceto no curso de Turismo, da Universidade Federal do Piauí (UFPI). Três sujeitos afirmaram que o vocabulário é a sua maior dificuldade. Já outro sujeito afirma que o estudo do léxico demanda um estudo aprofundado da língua (outros). Um informante respondeu que o grande problema é a falta de aula diária, ou seja, de segunda a sexta-feira.

Percebe-se, nas respostas acima, que a maioria dos respondentes aponta a falta de ensino da língua espanhola na cidade de Parnaíba (fora da universidade) como a maior dificuldade. Em segundo lugar, a dificuldade com o vocabulário, pois o idioma possui muitas palavras com sentidos e pronúncias diferentes.

A segunda questão buscava analisar a necessidade do turismólogo de aprender uma língua estrangeira, no caso, o espanhol, para poder se destacar no mercado de trabalho e, principalmente, no setor turístico. Visualizase, melhor, os resultados através do Gráfico 2 advindo dessa análise, a saber:

Gráfico 2: Necessidades de aprender uma língua estrangeira

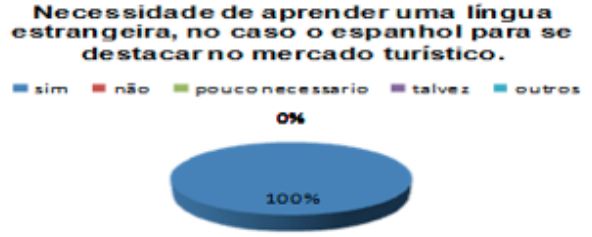

Fonte: Dados da pesquisa, 2013

Na segunda questão, foi perguntado aos sujeitos sobre a necessidade de aprender uma língua estrangeira, o espanhol, para se destacarem no mercado de trabalho. Todos os dez turismólogos responderam positivamente. Todos os sujeitos justificam que é necessário o conhecimento na língua espanhola para melhor atender aos turistas estrangeiros. Observou-se, ainda, que, na visão de todos os informantes, aprender uma língua estrangeira é necessário para o profissional de turismo porque ele trabalha diariamente com estrangeiros no setor turístico.

Na terceira questão, foi perguntado se o turismólogo deveria conhecer outra língua estrangeira. As respostas obtidas foram: todos afirmam que o conhecimento em outra língua é importante para a comunicação com os turistas estrangeiros, porque nos dias atuais é essencial saber outras línguas. A seguir, as respostas ${ }^{1}$ de cada in- formante, a saber:

- Informante 1: "Claro, como poderia falar com os turistas estrangeiros, entendê-los, se nem, ao menos conhecer a língua deles."

- Informante 2: "Sim, porque lido diretamente com pessoas, trabalho no qual a comunicação é imprescindível."

- Informante 3: "Sim, pois qualifica a atividade."

- Informante 4: "Sim, pois nos dias de hoje tornase quase que obrigatório o conhecimento em outra língua."

- Informante 5: "Sim, no mínimo uma segunda língua, o interessante é que fossem pelo menos três línguas diferentes para que pudéssemos atender melhor os nossos clientes."

- Informante 6: "Sim, é muito importante para a comunicação hospitalidade para com os estrangeiros."

- Informante 7: "Sim, para ter diferencial na profissão."

- Informante 8: "Sim, as oportunidades de trabalhar ficam ampliadas no mercado nacional e internacional."

- Informante 9: "Sim, qualidade técnicas e profissionais."

- Informante 10: "Sim, porque o turismo exige conhecimento em outras línguas devido ao turismo internacional, a qualquer momento podemos nos deparar com um turista com outro idioma."

Como se observa, os dez informantes afirmaram que sim, ou seja, acreditam que todo turismólogo necessita ter conhecimento em uma segunda língua. Foi observado, ainda, que a maior parte dos informantes afirma que é relevante para a comunicação no setor turístico para facilitar a interação entre visitante e visitado. Como afirma Bispo (2005, p.1) acerca das exigências do mercado de trabalho:

Quem ingressa no mercado de trabalho ou já exerce uma profissão há algum tempo, sabe que para assumir determinadas funções, muitas vezes, é preciso cumprir certos requisitos que vão além do diploma de um curso técnico.

\footnotetext{
${ }^{1}$ As respostas estão apresentadas tal como os sujeitos responderam nos questionários.
} 
Existem situações, por exemplo, em que é necessário dominar outro idioma para poder ter um bom desempenho. E quem imagina que saber outra língua é privilégio de quem exerce apenas um cargo de gerência ou diretoria, engana-se. Hoje, com o advento da globalização, profissionais dos mais diversos segmentos precisam lidar com expressões que não fazem parte do seu dicionário nativo, mas sim são originadas de outros países.

Buscava-se analisar na quarta questão alguma dificuldade encontrada na comunicação com eventuais turistas estrangeiros. As respostas obtidas mostram que, a maioria (70\%) afirma que as suas dificuldades estão relacionadas em explicar algum serviço para o turista estrangeiro. Outros aspectos relevantes que eles apresentaram foram: comunicação oral em diferentes contextos de uso, regionalismos e conhecimentos em outros idiomas. Veja, a seguir, o Gráfico 3 com tais dados coletados:

Gráfico 3: Dificuldade na comunicação com eventuais turistas estrangeiros.

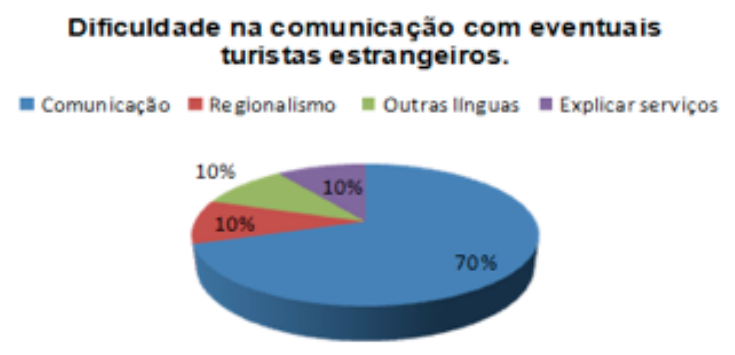

Fonte: Dados da pesquisa, 2013

A seguir, apresentam-se os dados informados pelos sujeitos do estudo:

- Informante 1: "Afirmou todas, pois não falo outra língua além da minha."

- Informante 2: "Sim, a pronúncia e os empecilhos questionados, falo não entendimento mútuo entre as partes."

- Informante 3: "Sim, em outras línguas como italiano e francês."

- Informante 4: "Sim, em se comunicar."

- Informante 5: "Sim, sempre, pois nem todos entendem o português."

- Informante 6: "Sim, na compreensão da língua."

- Informante 7: "Sim, dificuldade na hora de explicar serviços e passeios na região."
- Informante 8: "Sim, meu Espanhol e Inglês são muito limitados."

- Informante 9: "Sim, primeiro contato e os regionalismos na língua."

- Informante 10: "Sim, geralmente me comunicar com turistas que fala espanhol e italiano, mas tenho muita dificuldade com inglês."

A partir dos dados anteriormente apresentados, observa-se que os dez informantes afirmaram que, sim, ou seja, eles encontram alguma dificuldade em se comunicar com turistas estrangeiros. Os sujeitos afirmam que o principal fator é a comunicação e a falta de conhecimento em uma língua estrangeira. De acordo com Silva e Faita (2002, p.63) "Aprender a situação-alvo de cursos de línguas para profissionais do turismo é, na verdade, difundir um olhar sobre o seu trabalho. [...]."

$\mathrm{Na}$ sequência, na quinta questão, foi perguntado se os informantes tinham algum outro curso de língua espanhola, além do cursado na universidade, e a importância do conhecimento e aprendizagem dessa para sua carreia de profissional de turismo. Pode-se verificar tais dados expostos por meio do Gráfico 4, elaborado a partir das respostas dos sujeitos, a saber:

Gráfico 4: Curso de espanhol feito fora da universidade.

\section{Curso em língua espanhola que foi visto fora da universidade.}

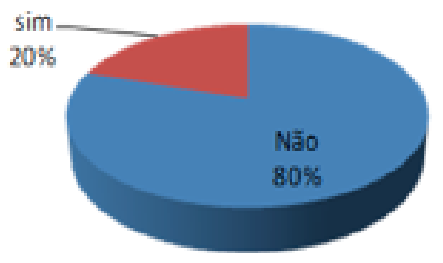

Fonte: Dados da pesquisa, 2013

A maioria dos informantes afirma não ter nenhum outro curso de língua espanhola, ou seja, oito sujeitos $(80 \%)$ responderam que não e dois sujeitos $(20 \%)$ responderam sim. O informante nove diz ter feito na $U n i$ versidad Autónoma de Guerrero/México e o informante dez cursou o nível básico no Centro Cultural de Línguas (CCL), curso ofertado pelo município de Parnaíba. Esse afirmou, ainda, que foi muito importante, pois ele consegue se comunicar, mesmo o curso sendo de nível básico. Desse modo, quem atua nessa área tem que se qualificar, no intuito de melhor receber tanto turistas domésticos quanto os visitantes estrangeiros, assim, gerando mais interesse por uma qualificação que atenda as 
exigências dos turistas e, com isso, desenvolvendo um turismo local de qualidade na cidade de Parnaíba.

Foi perguntado, na questão 6 , quais os cargos que exigem algum conhecimento da língua espanhola no seu ambiente de trabalho. A seguir, os resultados referentes a essa questão, a saber:

Gráfico 5: Cargos que exigem conhecimento do espanhol.

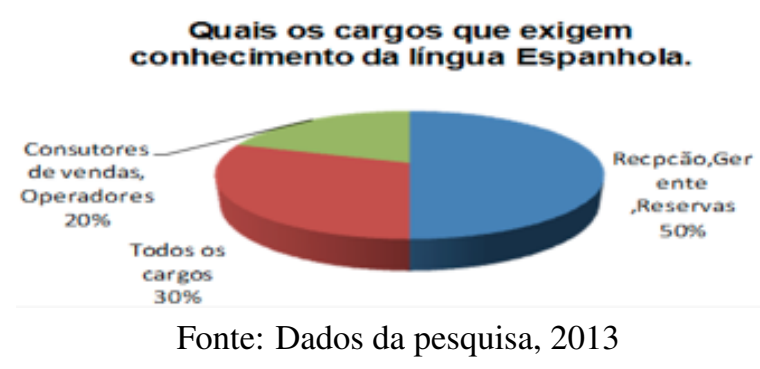

Notou-se, neste resultado, que a metade dos informantes afirma que todos os cargos exigem o conhecimento do espanhol e trinta por cento $(30 \%)$ afirma que os principais cargos são recepcionista, gerente e setor de reservas. De um modo geral, os dez sujeitos responderam que todos os setores necessitam de conhecimento em uma língua estrangeira, principalmente no caso de estudo em espanhol. Observa-se, ainda, que o conhecimento em uma língua estrangeira é imprescindível para o profissional que atua em uma empresa na qual ele precisa fazer uso constante de outro idioma. Como está exposto no Gráfico 5, observa-se que ficaram bem divididas as respostas dos informantes: $\operatorname{cinco}(50 \%)$ responderam que os setores que mais exigem conhecimento de língua espanhola são os de recepção e reservas; já $30 \%$, ou seja, três disseram que são todos os cargos que exigem conhecimento; e $20 \%$, dois, disseram que consultores de vendas e da administração e operadoras de turismo devem saber espanhol.

Para Marcondes (2001, p.1), "falar inglês naturalmente atualmente tornou-se um fator tão primordial quanto fazer o próprio nome." Nesse mesmo sentido, acredita-se, aqui, que ocorre a mesma situação em relação ao ensino e ao conhecimento da língua espanhola. Ao se referir à categoria administradora das empresas, o autor supracitado afirma claramente que "no mundo globalizado, em que qualquer pequeno deslize pode significar uma grande perda financeira ou mesmo de reputação, falar a língua mundial tornou-se uma questão de fundamental necessidade".

Na sétima questão, buscava-se saber qual a habilidade de comunicação mais usada em espanhol, no caso, fala ou escrita. Pode-se verificar tais dados expostos por meio do Gráfico 6, elaborado a partir das respostas dos informantes, a saber:
Gráfico 6: Habilidade de comunicação mais usada em espanhol.

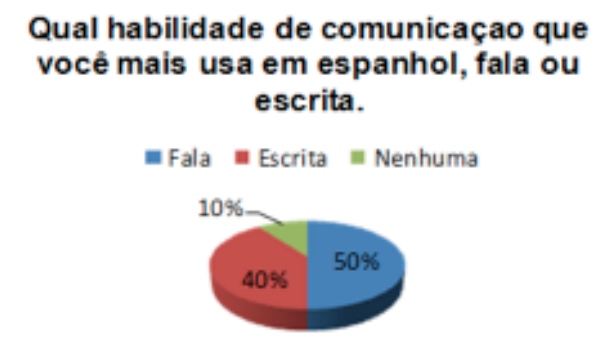

Fonte: Dados da pesquisa, 2013
Entre os dez informantes, $50 \%$, cinco, responderam que utilizam a fala para se comunicar em língua espanhola, e 40\%, quatro sujeitos, afirmaram que usam a escrita; somente um informante respondeu que não usa nenhuma habilidade e não justificou sua resposta. De acordo com os estudos de Freitas (2004):

\footnotetext{
É importante ressaltar que no trabalho dos agentes de turismo a atividade verbal é o essencial da tarefa e todo o fazer material se estrutura em torno da linguagem, seja oral, seja escrita. Na agência de viagens estudada, por seu caráter varejista e emissivo, quase a totalidade das interações orais é em português, com os clientes brasileiros e com as operadoras estabelecidas no país.
}

A oitava questão buscava averiguar qual a relevância da língua espanhola para a sua profissão de turismólogo. Veja o resultado no Gráfico 6

Gráfico 7: Relevância do espanhol para a profissão de turismólogo.

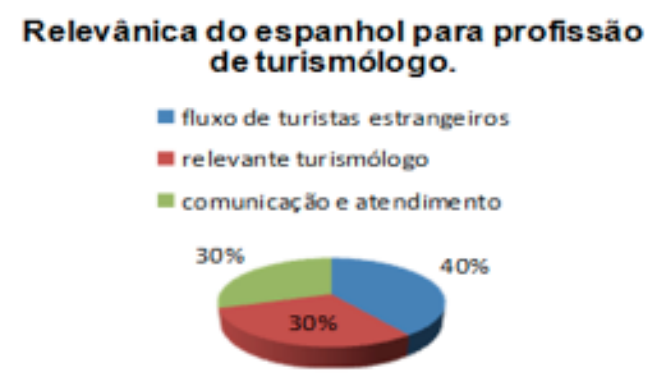

Fonte: Dados da pesquisa, 2013

Nesta questão, observa-se uma grande diferença entre as respostas. Devido às diferentes afirmações, tentase mostrar em forma de gráfico para as respostas ficarem mais evidentes e claras. Ficaram divididas assim: quatro sujeitos $(40 \%)$ afirmam que a relevância da língua espanhola está no fluxo de turistas falantes desse idioma no hotel onde trabalha; é o mais usado no con- 
tinente; aperfeiçoamento técnico na língua para melhor se comunicar na sua profissão com turistas estrangeiros. Três $(30 \%)$ afirmam que é um diferencial para sua profissão dominar outro idioma; esse grupo acredita que é importante para o seu ambiente de trabalho. Outros três sujeitos $(30 \%)$ dizem que é importante porque facilita o bom entendimento com os turistas, pois é uma habilidade muito importante e mais que necessária para uma boa comunicação. Nota-se, portanto, que os informantes afirmam que a língua espanhola faz parte do trabalho do profissional de turismo, consequentemente, possibilitando e facilitando o contato eficaz com diversas culturas. Segundos os referidos sujeitos, em primeiro lugar vem o inglês, em seguida, o espanhol; na ausência de uma, a outra supre; por isso, é relevante. Porém, o essencial é o conhecimento efetivo das duas línguas.

Na sequência, perguntou-se, na questão de número nove, com relação ao conhecimento de uma língua estrangeira, no caso o espanhol, se este idioma é critério decisivo na disputa de uma determinada vaga em uma empresa de turismo. Diante do Gráfico 8, pode-se observar as possíveis variáveis:

Gráfico 8: Conhecimento do espanhol como critério de disputa de vaga.

\section{Conhecimento do espanhol como critério de disputa de vaga}

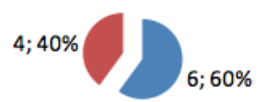

Sim

não

Fonte: Dados da pesquisa, 2013

De acordo com as respostas dos informantes, foi observado que seis sujeitos (60\%) responderam que não, ou seja, na cidade de Parnaíba ainda não é visto, para tais informantes, a língua espanhola como critério para disputar uma vaga de emprego, porém, em outras empresas do mundo, sim. Já quatro sujeitos (40\%) disseram que sim, quem tem conhecimento em outras línguas está na frente de quem não tem e, também, que, depende do cargo a se assumir; todavia, o inglês é o mais exigido, confirmando o comentário anterior. Desses quatro, um informante disse que isso se deve pelo fato do espanhol não ser a língua mais falada no mundo.

Ainda nessa questão, dois sujeitos afirmam que em Parnaíba as empresas não exigem qualificação em língua espanhola para contratações. Observa-se que a maioria dos informantes afirma que o inglês ainda é a principal língua exigida.

Parafraseando Sedycias (2000, p.2), a língua espanhola ocupa uma posição tão relevante recentemente quanto a da língua inglesa. Afirma, ainda, ser a língua espanhola a segunda língua mais utilizada no comércio internacional, e "quem decidir ignorá-la não poderá fazê-lo sem correr o risco de perder muitas oportunidades de cunho comercial, econômico, cultural, acadêmico ou pessoal". Segundo, ainda, o autor supramencionado, ele afirma que:

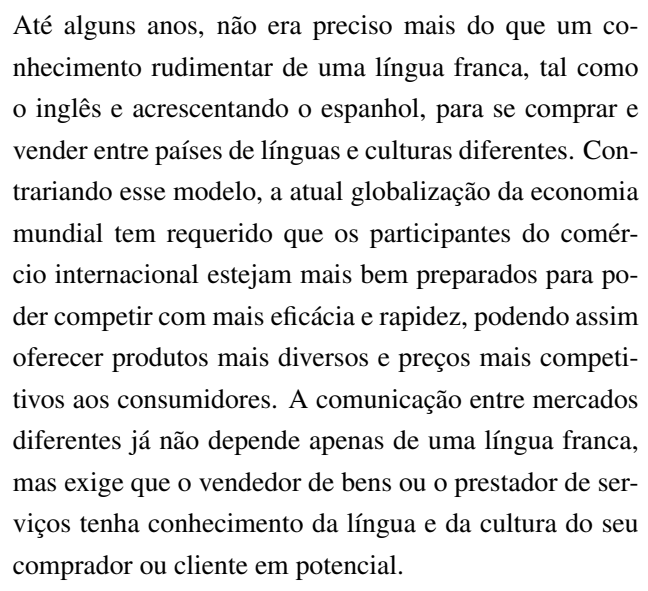

Na questão dez, pergunta-se sobre quais atividades o profissional de turismo necessita fazer uso de alguma habilidade em espanhol como, por exemplo: leitura, escrita, audição. Ilustram-se, abaixo, os dados obtidos a respeito deste tema, os quais são apresentados no Gráfico 9 .

Gráfico 9: Atividades que exigem o conhecimento do espanhol.

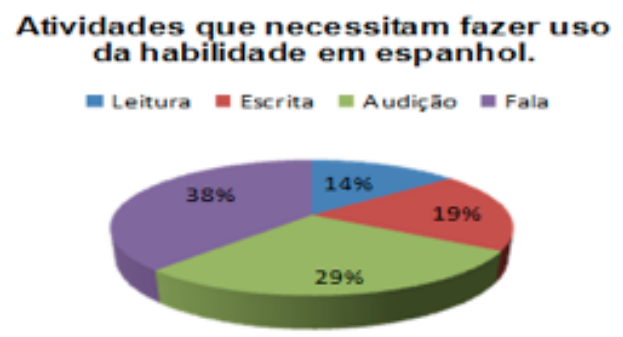

Fonte: Dados da pesquisa, 2013

A maior parte dos informantes afirma que suas maiores necessidades de fazer uso da língua espanhola referem-se à habilidade da fala, quer dizer, a maior necessidade refere-se ao ato de comunicar-se oralmente com clientes e turistas estrangeiros, nesse caso, oito sujeitos $(38 \%)$. Desses oito sujeitos, dois dizem fazer uso de todas as habilidades por estarem recebendo turistas, quer dizer, atendem telefone, respondem a e-mail, vendem produtos das agências, fazem contato com operadoras estrangeiras, realizam contratos com parceiros in- 
ternacionais, mantém contatos com portais de hotéis, etc.

No entanto, dos sujeitos que atuam nos três hotéis, três sujeitos (14\%) dizem utilizar com frequência a leitura, enquanto um sujeito diz utilizar a leitura meramente para estudar. No tocante à audição, obteve-se que seis sujeitos $(29 \%)$ dizem fazer uso dela nas suas atividades, e à fala, oito sujeitos $(38 \%)$ utilizam para $\mathrm{o}$ atendimento a turistas e/ou clientes. Por fim, quatro sujeitos (19\%) utilizam para realizar reservas, atuar na recepção, anotar recados, quer dizer, várias das habilidades. E somente dois sujeitos não responderam a décima questão.

De acordo com Castelli (2001), por meio da educação e do treinamento pode-se acrescentar mais valor as pessoas, tornando-as mais capazes, pois a excelência dos bens e serviços depende da qualidade dos serviços e esses da qualidade das pessoas que o executam. Funcionários com qualidade pessoal elevada são, pois, um importante ativo para qualquer empresa. Nesse sentido, nas considerações do autor supracitado, nota-se que, perante o ensino e a aprendizagem de uma língua estrangeira, por exemplo, tal conhecimento torna as pessoas mais qualificadas e capazes de superar obstáculos e executar com qualidade as suas atividades no tocante ao seu cargo profissional.

\section{CONSIDERAÇÕES FINAIS}

O presente trabalho se propôs a detectar e analisar as crenças acerca da relevância da língua espanhola para o turismólogo de Parnaíba e sua importância para o desenvolvimento do turismo local. A partir dos resultados coletados durante a pesquisa, conclui-se que os profissionais de turismo que atuam no setor hoteleiro e nas agências de viagens não estão devidamente qualificados para se comunicar e, também, para receber turistas estrangeiros com relação ao conhecimento da língua espanhola. As suas principais crenças estão na falta de escolas de idiomas qualificadas e o maior conhecimento lexical da língua espanhola, por exemplo.

De acordo com o corpus, percebeu-se que a maioria dos turismólogos afirma que suas maiores dificuldades estão na falta do ensino da língua espanhola, que ainda não é muito difundido na cidade de Parnaíba. Além disso, os sujeitos afirmam que sentem dificuldades com o vocabulário da língua, o qual possui muitas palavras com sentidos e pronúncias diferentes.

Tais informantes dizem, também, que é necessário aprender uma língua estrangeira (LE) para se destacar no mercado turístico, pois o profissional dessa área pode se deparar com turistas estrangeiros. Foi perguntado aos turismólogos se todo profissional de turismo deveria conhecer uma segunda língua e todos os sujeitos julgam ser essencial, pois essa atividade lida com pessoas e culturas diferentes e todo profissional deve conhecer outro idioma, pois a comunicação em LE promove ao profissional um leque de oportunidades, tanto no mercado nacional quanto no internacional, uma vez que, no setor hoteleiro, todos os cargos necessitam de conhecimento em LE.

Os resultados coletados revelam que a língua espanhola pode ser considerada como critério decisivo na disputa de uma vaga de emprego em uma empresa turística. Observou-se que a maior parte dos sujeitos diz que na cidade de Parnaíba não é visto isso e que o inglês é mais exigido por ser a língua mais falada no mundo. Segundo os profissionais pesquisados, a habilidade mais utilizada por eles é a fala, pois estão em contato direto com os visitantes estrangeiros. Também afirmaram ser a segunda habilidade linguística mais utilizada é a auditiva, porque eles mantem contato por telefone e, por último, a habilidade escrita, por fazerem as reservas, realizar vendas de pacotes, contato com operadoras através de e-mails, etc.

A pesquisa, inicialmente, seria realizada com todos os profissionais turismólogos que atuam em todos os hotéis e agências de viagens e turismo de Parnaíba; contudo, devido à dificuldade de encontrar tais profissionais em todos os hotéis e agências, a pesquisa foi realizada em três hotéis e duas agências de viagens e turismo.

Por fim, espera-se que, apesar das limitações, este estudo tenha apontado na direção de novas investigações que induzam o acadêmico e o futuro profissional de turismo o interesse em buscar cada vez mais o aprendizado e o conhecimento das línguas estrangeiras que já estão atuando no campo do Turismo no Brasil, inclusive, o conhecimento efetivo da língua espanhola.

Dessa forma, acredita-se que a língua espanhola possa ter um papel importante na potencialização do profissional de turismo, facilitando a comunicação entre visitante e visitado e desenvolvendo a entrada de novos turistas estrangeiros, como também facilitar aos empreendimentos a comunicação com os visitantes e a permanência do turista, pois esse turista, observando que foi bem recebido e compreendido em sua língua, pode retornar outras vezes.

\section{REFERÊNCIAS}

ALMEIDA FILHO, J. C. P. de. Dimensões

comunicativas no ensino de línguas. : Pontes Editores, 1993. 
CRENÇAS DOS PROFISSIONAIS DE TURISMO SOBRE A RELEVÂNCIA DO ENSINO DE ESPANHOL COMO LÍNGUA ESTRANGEIRA - ELE

ALVAREZ, M. L. O. S.; SILVA, K. A. Crenças, motivações e expectativas de alunos de um curso de formação letras/espanhol. In: Lingüística Aplicada: múltiplos olhares - Estudos em homenagem ao Professor Dr. José Carlos Paes de Almeida Filho. : Pontes Editores, 2007. p. 191-231.

BARCELOS, A. M. F. Metodologia de pesquisa das crenças sobre aprendizagem de línguas: estado da arte. Revista Brasileira de Linguística Aplicada, v. 1, n. 1, p. 71-92, 2001.

. Crenças sobre aprendizagem de línguas, linguística aplicada e ensino de línguas. Linguagem e Ensino, v. 7, n. 1, p. 123-156, 2004.

BARCELOS, A. M. F.; ABRAHÃO, M. H. V. Cognição de professores e alunos: tendências recentes na pesquisa de crenças sobre ensino e aprendizagem de línguas. In: Crenças e ensino de línguas: foco no professor, no aluno e na formação de professores. : Pontes, 2006. p. 15-41.

BISPO, P. Inglês para executivos e chão de fábrica. 2005. Disponível em: <http://www.rh.com.br/ler>.

CARVALHO, A. da R. Um Estudo sobre a formação em inglês de profissionais de turismo em Fortaleza. Dissertação (Monografia de Especialização) Universidade Estadual do Ceará, Fortaleza, 2003.

CASTELlI, G. Administração Hoteleira. : Educs, 2001.

CORTICEIRO, A. C. A utilização da língua inglesa como ferramenta de promoção na cidade de Aveiro. Dissertação (Dissertação de Mestrado) — Universidade de Aveiro, Aveiro, 2008.

FREITAS, L. M. A. Espanhol para o turismo: $o$ trabalho dos agentes de viagens. Dissertação (Dissertação de Mestrado) — Universidade Estadual do Rio de Janeiro, Rio de Janeiro, 2004.

KEZEN, S. O ensino de língua estrangeira no Brasil. 2005. Disponível em: <http: //www.fdc.br/lingua_estrangeira.htm $>$

LEFFA, V. J. O computador no ensino de linguas; estado da arte e tendencias. Tecnologia Educacional, v. 20 , n. $102 / 103$, p. 23-28, 1991.

MARCONDES, C. Do you speak English? 2001.

Disponível em: <http://www.unicainformatica.com.br/ conteudo.asp?conteudo $=115>$
RICHARDS, J. C.; LOCKHART, C. Teacher development through peer observation. TESOL Journal, v. 1, n. 2, p. 7-10, 1991.

SABOIA, A. L. A transculturalidade a partir do uso de textos literários no ensino de E/LE: crenças de professores formadores e em formação do curso de Letras Espanhol da UERN (CAMEAM). Dissertação (Dissertação de Mestrado) — Universidade Estadual do Ceará, 2012.

SANCHES, C. Dominar outro idioma é uma necessidade profissional. Gestão RH online, n. 15, p. 30-35, 1997.

SEDYCIAS, J. Por que os brasileiros devem aprender espanhol? 2000. Disponível em: <http: //home.yawl.com.br/hp/sedycias/porqueesp.htm>

O Ensino do Espanhol no Brasil: Passado, Presente, Futuro. : Parábola Editorial, 2005.

SILVA, M. C. S. e; FAITA, D. Linguagem e trabalho - construção de objetos de análise no Brasil e na França. : Editora Cortez, 2002.

TONDELLI, M. de F. A influência da língua estrangeira na empregabilidade de profissionais da área tecnológica no setor industrial: Um estudo exploratório na região norte do Paraná. Dissertação (Dissertação de Mestrado) — Universidade Tecnológica Federal do Paraná, Ponta Grossa, 2005. 